\title{
Censura y creación literaria I. Entrevistas a Antonio Ferres y Juan Mollá
}

\author{
María Álvarez Villalobos \\ Universidad de Alcalá, España \\ Cristina Suárez Toledano \\ Universidad de Alcalá, España
}

Todas las obras literarias que se publicaron en España entre los años 1938 y 1978 debieron someterse a la inspección de la censura franquista. Amparados por dos leyes de prensa sucesivas (una de 1938 a 1966 y otra de 1966 a 1978), los censores que trabajaban para el Ministerio de Información y Turismo organismo responsable de este sistema de vigilancia y represión- se encargaban de leer los manuscritos que les enviaban las editoriales teniendo que emitir un informe al respecto, además de proponer una de las siguientes resoluciones: a) su autorización íntegra; b) su autorización con tachaduras, práctica muy común en tanto que se eliminaban las palabras y los pasajes considerados de mayor conflictividad; o c) su denegación, siendo esta más que probable si entendían que el texto en su totalidad constituía un ataque al dogma religioso, a la moral católica, a la Iglesia o a sus Ministros, al régimen, a sus instituciones y a sus colaboradores. Los expedientes de censura que contienen estos informes se encuentran, a disposición pública, en el Archivo General de la Administración, en Alcalá de Henares (Madrid).

En el año 2018, animadas por el profesor Fernando Larraz y como punto de apoyo para basar nuestras respectivas investigaciones -directamente relacionadas con la censura editorial franquista-, elaboramos un cuestionario formado por varias preguntas que abarcaban diversos aspectos generales, si bien luego se concretaban para acercarse a la trayectoria literaria de cada autor de forma específica. El objetivo principal era conocer de primera mano cómo vivieron los escritores esa problemática y cómo afectó a sus obras. Esos testimonios se configurarían así como una fuente oral para nuestros trabajos. Decidimos entonces entrevistarnos con autores que hubieran sufrido en sus trayectorias literarias el trato con la censura, dificultando que los lectores españoles pudieran leer sus textos tal y como fueron concebidos originalmente. Tras ponernos en contacto con ellos, tanto Antonio Ferres como Juan Mollá accedieron amablemente a entrevistarse con nosotras en persona en marzo del mismo año. Los dos, además de pertenecer a una misma franja generacional, comenzaron a publicar su obra narrativa en 1959 -Ferres con La piqueta y Mollá con Sueño de sombra (en colaboración con Víctor Alperi) - y tuvieron que acogerse en sus inicios en el mundo literario a la primera ley de prensa franquista. Sus siguientes textos debieron someterse también a la Ley de Prensa e Imprenta de 1966, por lo que no pudieron ver la luz con total libertad hasta los años ochenta del siglo pasado.

\section{Entrevista a Antonio Ferres}

Antonio Ferres (Madrid, 1924) es un autor que, adscrito a la llamada "Escuela de Madrid" y la "Generación del Medio Siglo", o "del 50", está considerado como uno de los máximos representantes del realismo social de la literatura española del siglo XX. Tras marcharse de España en los años sesenta, ejerció como profesor de Literatura en Estados Unidos y en México hasta que regresó a Madrid. Su trayectoria literaria es amplia. Ha publicado más de una veintena de obras, entre las que destacan títulos narrativos como La piqueta (1959), Los vencidos (1962, en su edición italiana), En el segundo hemisferio (1970) y $\mathrm{Al}$ regreso del Boiras (1975). En las últimas décadas, se ha centrado en el cultivo del relato y la poesía, en títulos como La urraca y los días 
iluminados (2012) y El libro de los cambios y las hojas (2013), todos ellos publicados por la editorial Gadir. Además, en 2002 publicó Memorias de un hombre perdido, volumen en el que relata parte de sus vivencias. María Álvarez Villalobos y Cristina Suárez Toledano: ¿Cómo eran la censura y el régimen franquista?

Antonio Ferres: Depende. Depende de la editorial, depende del autor, depende de todo. El franquismo dura mucho, es la dictadura que dura más después de la de Porfirio Díaz en México, que era la más larga en el mundo. Ha habido dictaduras en el mundo, pero como la de Franco, de larga, no la ha habido. Fíjate en la diferencia que va cuando Franco está aliado con los que van ganando a cuando se derrumba el Eje y, claro, como es un hijo de puta, pero es nuestro hijo de puta, como creo que decía Eisenhower, vienen y hacen bases aquí y ya empieza la Guerra Fría y por eso dura tanto, hasta que se muere Franco. Cuando se empiezan las bases yo me acuerdo que iba a Francia y me encontraba con los exiliados y me decían: "esos nos lo ponen en bandeja de plata, macho", los socialistas, que sobre todo vivían en Toulouse. Toulouse era una ciudad socialista española y yo les dije "hasta que no se muera..." y eso fue lo que pasó. Y por eso tenía ese complejo de inferioridad todo Occidente, de ayudar a la Transición, cosa que no hicieron en absoluto con Portugal. En la Revolución de los claveles no hubo ni un muerto y aquí con ETA... muertos y terrible. La Transición fue con mucha sangre y sin embargo odiaban a la Transición porque eran unos chavales ingenuos que se declaraban comunistas y querían nacionalizar la banca, etcétera.

M.Á.V. y C.S.T.: Pese a su fuerte carácter de crítica social La piqueta pasó la censura. ¿Cómo fue esa historia?

A.F.: Simplemente porque era Destino. Yo imagino que fue así: Destino era una editorial formada en zona nacional, con falangistas catalanes que se pasan por el Pirineo a zona nacional. Cataluña y esa zona era republicana, o como quieras llamarle. Se pasan al otro lado y en Burgos establecen una revista, que es la revista Destino. "Destino" es por "España, unidad de destino en lo universal" que es una frase de José Antonio Primo de Rivera, que es el que está en el Valle de los Caídos con Franco. Esa gente, como Porcioles, que fue alcalde de Barcelona, eran amigos de Franco, o como Vergés, que fue el director de Destino. Tienen un trato distinto. España pasa una época de nacional-catolicismo. Todos tenemos fotos de Franco bajo palio y con los obispos y el brazo en alto. Esa época no es lo mismo que la otra y entonces cambia. Pasan la censura como el agua.

La novela es una historia de amor y tiene un fondo épico porque el chico, que va a ser el que recoge a Maruja, tiene características de héroe clásico. Ha sido desenterrado de un bombardeo, tiene una cicatriz en la cara y está viviendo con los tíos porque sus padres han muerto, como los de todos los héroes clásicos. La chica llora y todo, porque se tiene que ir con él y rompen todas las convenciones, porque no se van. Esa amalgama es la que hace La piqueta. El narrador cree que va a haber una sublevación como ahora con los desahucios, pero entonces lo que pasa es que se crea un gran problema porque dónde van los niños... Siempre el escritor busca tono. El tono es la unicidad con la que vas a escribir, la actitud narradora. Yo me inventé a un cronista, que es el que escribe en cursiva el principio y el final. En ese tiempo está de moda el behaviorismo, así que yo tengo que hacer que sea él quien escriba la novela. Él tiene que ser más culto que yo, por eso habla de las arenas miocénicas, para que sea él quien hable. Decían que era una novela costumbrista. En Orcasitas es algo y fuera yo creo que ya no es nada.

\section{M.Á.V. y C.S.T.: ¿Cómo fue su relación con Vergés y con Destino?}

A.F.: Rafael Vázquez Zamora era el secretario del Premio Nadal, que era el premio de más prestigio. Al mismo tiempo, era secretario del Premio Sésamo. Yo soy el segundo Premio Sésamo (por mi cuento "Cine de barrio"), el primero fue Jesús López Pacheco. Él nos dijo: "Destino, que os publica a vosotros, no os va a dar el Premio". La primera novela que se publicó en Destino sin que la tocara la censura fue Central eléctrica, de López Pacheco. Luego sale la mía (La piqueta), luego sale La mina, de Armando López Salinas, y luego sale La zanja, de Alfonso Grosso. Los cuatro éramos del Partido. A mí ni en la editorial ni en la censura me tocaron nada y salió. En cierto modo, tampoco es para tanto, porque eso estaba ocurriendo. Lo que hago yo es que busco un escritor omnisciente que es una persona culta. Se ve que ese señor es el que ha escrito la novela, no yo. Y ese señor, que es un hombre culto, dice al final: "En apariencia, no ocurría absolutamente nada. Solo el sol caía sobre las arenas del Mioceno, por los campos donde termina una triste y pobre ciudad”. Ahí está 
el problema, que no ha ocurrido absolutamente nada. Ha ocurrido todo, pero no ha ocurrido nada, pero lo demás es una cosa normal.

Abandoné Destino el día que me llama por teléfono Carlos Barral desde Barcelona, que estaba con Castellet. Vienen y me dicen: "Antonio, nosotros queremos una cuadra de escritores. Si lo prohíben aquí, lo publico fuera", que es lo que pasó con Los vencidos, que se vendió a Feltrinelli. Me dijeron que llamara por teléfono a Vergés y le dijera que el contrato que tenía con ellos era leonino, que podían decir que tenía preferencia de edición, pero no que todos los libros eran suyos. Barral quería contratar el libro, pero estaban por delante ellos. Desde ese momento salimos en Barral.

M.Á.V. y C.S.T.: ¿Cómo fue entonces su relación con Barral?

A.F.: Cuando Carlos Barral llega a Madrid, se aloja, como es un señorito y tiene mucho dinero, en el Hotel Suecia. Íbamos nosotros a verlo. Sería una gracia porque élllegaba y decía "un whisky" y nosotros decíamos "un café solo". Éramos los pobres los de Madrid. Entonces, el tío nos dice "os venís conmigo" porque éramos todos los que nos fuimos, por ejemplo, la gente que era de Destino. Cuando íbamos a ver a Carlitos, llegábamos allí y tenía un yate y todo eso en Calafell. Íbamos a Calafell de vez en cuando y nos quería mucho.

Yo escribo Los vencidos y Barral la coge y la pasa a censura. La censura venía diciendo "el asunto cuatrocientos treinta y tantos del Ministerio de Información y Turismo se resolverá de la forma que se señala en la hoja adjunta", y en la hoja adjunta ponía "prohibida su publicación en España". De esa manera, decíamos "este señor está exagerando". Yo no sé por qué lo hacían así, era como una dictadura vergonzante porque, claro, ya entonces en el mundo entero no había otra dictadura así. Mi novela la cogió Barral y la mandó inmediatamente a Feltrinelli, por eso Los vencidos sale primero en italiano, I vinti. A mí me viene bien casi porque se traduce a muchos idiomas. ¿A mí qué me hacen? Qué me van a hacer, si yo era incluso oficial de Franco. Los estudiantes íbamos a lo que se llama Instrucción Provincial Superior, que se llamó "Milicia Universitaria" en los primeros años. Yo soy oficial y dije "bueno, esto te lo ha hecho la guerra" y entonces yo hago una novela mucho más fuerte, que ya no pasó y fue terrible.

M.Á.V. y C.S.T.: Cuando estaba escribiendo primeras obras como esas, ¿se planteaba que tenian que pasar la inspección de la censura?

A.F.: Sí, claro que te lo planteas. Por ejemplo, en Los vencidos iban a cortar ya por el título. Salió también en español en París en Editions de la Librairie du Globe que compartió mucho el PC. Yo me hice del Partido Comunista y éramos todos comunistas, pero ninguno lo decía. Tú cuando un tío decía que no era comunista, no era así. Cuando yo me fui la primera vez de España, lo digo siempre, me fui por miedo, por un día que me dio miedo y me dije "me tengo que ir porque aquí no hago nada". Un día decidieron en la Universidad los estudiantes de izquierdas, que ya estaban revolucionados, hacer un homenaje porque habían detenido a mujeres de mineros y había una represión terrible y además por qué íbamos a tener que pagar el SEU. Había un sindicato obligatorio y tenías que pagarlo. Y decían que por qué tenías que pagarlo, que si querías sí pero que si no, no. Pedíamos esas cosas. Total, aquello iba a estar bien. Íbamos a estar García Hortelano, Antoñito Martínez Menchén, que es el hermano de Andrés Sorel, que ha dejado de escribir pero que publicó alguna colección de cuentos incluso en Seix Barral, y yo. Y quedamos en el Laurel del Baco, que era una cervecería que ya no sé si existe, y nos juntamos allí todos y de repente llegan los estudiantes y dicen "no se puede entrar, está todo lleno de policía". García Hortelano se fue y yo seguí tomando una cerveza y vino Armando: “¿qué pasa?", "pues que no va a haber nada". Y de repente viene otro estudiante y dice "hemos roto las cadenas, hemos abierto y hay un aula que hemos quitado todo y solo hay la mesa del profesor para que subáis ahí de pie". Y nos llevaron como en volandas y entramos allí y nos subimos a la mesa Armando y yo, porque los demás se habían ido. Armando es el de La mina, que además hizo conmigo Caminando por las Hurdes. De repente, empiezan a tirar octavillas: "los comunistas saludamos". Y le digo a Armando: "va a venir la policía". Y les digo: "señores, esto nosotros no tenemos que ver con ello". Pero como hay que hablar luego, porque si no eres un cobarde, pues pusimos a parir hasta a Franco. En las dictaduras hay que luchar contra ellas, pero hay que decir que Franco sigue porque está enajenado por algo pero hay que darse cuenta, "a este pobre hombre 
qué le pasará, no se da cuenta cómo este país va”. Total, después de ese meeting que dimos ahí, nos fuimos a casa y toda la noche, cuando sonaba el ascensor: "Dios mío, la policía", que luego no vino la policía ni nada, pero pasé un miedo terrible.

M.Á.V. y C.S.T.: ¿Y Y por quése fue la segunda vez?

A.F.: La segunda vez me fui por hambre.

M.Á.V.y C.S.T.: ¿Y qué hay de la autocensura?

A.F.: Sin duda, la autocensura está en cualquier dictadura. Es más, yo creo que siempre hay autocensura. Siempre. Pero ya en una dictadura no digamos porque, claro, no va a poderse publicar. Vendrá el papelito "prohibida su publicación en España" y ya está.

Me acuerdo de un libro mío que era Mirada sobre Madrid, que era de Castellet en Edicions 62, que era en catalán, pero había luego libros en castellano en Península. Me llegaron a mí a Indiana las galeradas y veo que se han cargado todo el final porque es un libro reportaje sobre Madrid. Entonces me dijo "arréglalo" y yo lo arreglé de cualquier manera y pasó.

Claro que hay autocensura, siempre. Yo en Los vencidos puse un personaje, el médico de la cárcel, que es un recluso y una persona culta, que se hace amigo del jefe de los presos y le dice "¿usted se da cuenta de que un día tendrá que reconciliarse el país? En todas las guerras civiles ha pasado. ¿Usted se cree que tienen que ver estos presos con los que han matado a su gente?”. Claro, eso no les gustó y se la cargan. Yo solo respondo de la edición de Gadir de Los vencidos porque en alguna hay muchos cambios, como en la edición alemana. Por ejemplo, he visto algunas traducciones que cambian el final, pero lo que quiero decir con esto es que salió en todas partes: primero en italiano y luego acabó saliendo incluso en español.

M.Á.V.y C.S.T.: ¿En qué momento y por qué decidió hablar sobre los vencidos de la guerra?

A.F.: Los vencidos está hecha a la vez que La piqueta. Yo conocí a un médico que estaba preso. No me acuerdo de cómo se llamaba. El problema no es entre presos de la cárcel, sino que al final la gente tiene que entenderse. Es un poco la reconciliación nacional. Yo pensé que iba a pasar, que como mucho iban a cortar fragmentos, pero que iba a pasar. Pero se la cargan porque hay fusilamientos.

M.Á.V. y C.S.T.: ¿Cree que, en parte, los problemas para la publicación en España de Los vencidos pudieron tener que ver con la relación previa de Seix Barral con la censura?

A.F.: A Seix Barral no le daban ningún trato de favor al principio, pero después, sin embargo, Barral sí tuvo una cosa buena cuando entran los latinoamericanos. Por ejemplo, La ciudad y los perros, de Mario Vargas Llosa, Premio Nobel. Recuerdo haber hecho una crítica que está en Cuadernos para el diálogo, la revista de la democracia cristiana y que dirigía nada menos que Ruiz-Giménez, que fue ministro con Franco pero que luego acabó en la cárcel. Yo dije que era estupenda, pero que si el tema hubiera sido España no hubiera pasado. Primero, escatológicamente no es lo mismo decir "qué hijo de la chingada" que "qué hijo de la gran puta" para un censor porque "hijo de la gran puta" lo quita e "hijo de la chingada" piensa que solo son esas cosas que decían los mexicanos. Eso es lo de menos ya, esas frases. Segundo, es que es un colegio militar, pero imagínate que fuera un colegio militar franquista, del ejército, pues no pasaría la censura esa novela. Vargas Llosa se encuentra con eso. Tanto es así que me llamó Barral por teléfono y me dijo "a mí me ha gustado mucho la crítica y creo que a él también le ha gustado, pero a lo mejor se enfada porque tú has dicho eso", pero es que era verdad. Yo tengo que decir la verdad en una crítica porque si no, no la escribo y yo digo que me gusta la novela por esto, por esto y por esto, pero que la novela no hubiera pasado si fuera española porque es verdad. ¿Por qué salía en Cuadernos para el diálogo? Bueno, porque querían apertura y de alguna manera decían "¿quién lee Cuadernos para el diálogo?” y, claro, la democracia cristiana pensaba que iba a ser lo que iba a superar al franquismo.

M.Á.V. y C.S.T.: ¿Cómo era la primera ley de censura? ¿Cómo afectó a sus primeras obras?

A.F.: Eso sabréis vosotras más que yo porque habéis mirado las leyes, pero yo me acuerdo de haber ido con un grupo de escritores a ver al cuñado de Fraga, que era entonces el que llevaba la censura, Robles Piquer. Me dijo Robles Piquer "pero cómo escribe usted esa novela". Al regreso del Boiras. Al regreso del Boiras es 
mi novela más ambiciosa y no salió hasta muchísimos años después. En Venezuela salió con un yugo y unas flechas en la portada, que lo hizo Ricardo Zamorano, que era un grafista y grabador importante. La novela mía más atrevida es, sin duda, Al regreso del Boiras, porque todo eso que yo cuento es verdad. Y estaba en ese momento en el que no sabes lo que va a pasar, pero el hecho es que yo conservo los nombres de los tíos, y ahí fueron los requetés que bajaban y mataban a la gente que no iba a misa y a los que iban porque decían que tenían unos cepos en la boca para matar la hostia. Claro, eso lo ve la censura, pero eso se lo dije a Robles Piquer: "es una consecuencia por la prohibición de Los vencidos". Yo eso lo hice a mala leche. Hay una cosa que no hay que olvidar. Yo soy oficial del ejército de Franco. Somos niños de la guerra.

Es una novela que es de lo más terrible que se ha escrito jamás. Yo me fui a la Bureba, que es una zona de ovejas en la provincia de Burgos, vertiente del Ebro ya. El Boiras es el que regresa, que ha estado allí en la cárcel. Hay mucha diferencia porque aquí de la cárcel sales y ya está, pero en esas zonas... Y ahí no fueron los falangistas, la represión gorda fue de los requetés navarros. Le habían matado a todos los hermanos y lo que planteo yo ahí es casi como Pedro Páramo, es un mundo de muertos, de vivos..., porque es que no se sabía lo que iba a pasar. Hemos tenido una suerte bárbara con la Transición.

M.Á.V. y C.S.T.: ¿Y qué hay de la Ley del 66?

A.F.: Al principio era mucho peor, pero también dependía mucho. Con la ley del 66, con Fraga, es algo mejor. Sí que se notó una apertura, pero, bueno, como era tan arbitraria la censura, no os quepa la menor duda de que si un tío está reconocido como rojo no le dejan publicar, no es lo mismo que, por ejemplo, Cela.

Una vez, la Asociación de Amigos de la UNESCO me mandó lo que constaba en la Dirección General de Seguridad de mí y decía: "asistió a una manifestación comunista y fue detenido". Eso está contado en un libro mío, de la editorial Pretextos, que se llama Los confines del reino, que es una novela autobiográfica. Yo cuento que tuve una entrevista con Santiago Carrillo. De ese libro no salió ni una crítica, y ya se había muerto Franco. A mí me dijo Vázquez Montalbán que me iba a contar lo que pasó con el periódico El País, pero luego murió y no me lo contó. Seguramente, él trató de hacer una crítica de esto y, claro, como yo me metía con Santiago Carrillo de alguna manera, El País no lo saca. Este libro salió en el 97. Yo cuento que fui con Caballero Bonald, que hoy día es Premio Cervantes nada menos, y con Ebbe Traberg, que era un especialista en jazz y un gran poeta danés que no sabía casi español pero era corresponsal aquí. Íbamos los tres y entonces vemos que en la puerta del Sindicato Vertical, que estaba frente al Museo del Prado, que hoy es un ministerio, había unas carreras de unos cuantos obreros corriendo y estaba llena de coches de policía. De uno de los autobuses de policía nos dicen “idelante! ¿qué hacen aquí?” y nosotros “nada, estamos mirando”. Y nos dijeron “fuera, deprisa, ¡ligero, ligero!”. Y entonces Traberg creyó que me insultaba porque lo relacionó con "ligero de cascos". El hecho es que me cogen y me llevan al autobús. A mí me detienen y al momento en todo el mundo: "Un escritor, Antonio Ferres, ha sido detenido por la policía". Me llevaron a la Dirección General de Seguridad, que estaba en la Puerta del Sol, donde hoy está la Comunidad Autónoma de Madrid. Me llevaron ahí y había una puerta que ponía "Represión de Masonería y Marxismo” y me quedé allí toda la noche y por la mañana me dijeron "usted ha estado en una manifestación" y yo dije "en una manifestación de guardias, de policía armada, porque he visto ocho o diez obreros corriendo". “ $i$ Tiene usted una multa!” y, claro, nosotros teníamos orden, bajo cuerda del Partido, de no pagar multas y de ir a la cárcel si hacía falta, así que yo dije "yo no tengo dinero, iré a la cárcel". "Pues tiene usted veinticuatro horas: o paga, o es usted detenido y va a la cárcel”. Bueno, pues llego yo de mañana a mi casa y me dicen "Dios mío, ¿dónde estabas? ¿detenido?" y digo "sí, eso ha pasado, tengo que pagar eso o iré a la cárcel”. A las dos horas o así, un motorista: "ha sido sobreseído". Y por eso consta que yo he estado detenido: he estado una noche en un sofá, ni siquiera en los calabozos. Ellos piensan "joder, este tío vale más muerto que vivo. ¿Qué puede hacer este tío? No puede hacer nada". Sin embargo, hace mucho daño porque ya ven que están diciendo por ahí que lo han detenido, porque Ebbe Traberg era un corresponsal aquí. No hay escritores que después fueran a la cárcel por cosas de censura. Debía de haber orden de no meter en la cárcel por esto.

M.Á.V.y C.S.T.: ¿Y qué ocurrió con el resto de sus obras censuradas? 
A.F.: Lo que pasa es que yo soy un escritor maldito. Mi primer cuento es uno que se llama "Cañas dulces" que, en pleno franquismo, Juan Eduardo Zúñiga se lo dio a Carlos Edmundo de Ory, que era un poeta surrealista muy interesante y un hombre muy culto, que dijo "esto va a pasar censura porque no parece España". "Cañas dulces" es un cuento muy breve. Es un tipo que va a matar al patrón y tiene una china en el zapato, y cuando lo mata se quita el zapato y se quita la china. Es como una broma. Es en una tierra de monocultivo, un latifundio de caña de azúcar de España. No saben nada porque como este es un país de ignorantes, la censura también se cree que eso es Latinoamérica y dice "caña de azúcar aquí no hay", pero ¿cómo que no? Aquí hay ingenios y la caña de azúcar va a Cuba desde Granada. Había ingenios en Almuñécar, Salobreña, Motril... Lo publiqué en un almanaque de El Grifón, que era una revista que salía en el franquismo. Es que ocurrían cosas insólitas: salían revistas, no salían, las retiraban...

Sabéis que Barral rompe con Seix y, como las leyes son así, los Barral se retiran, pero los Seix siguen publicando y Seix Barral sigue siendo una editorial que no tenía ya que ver con Barral. Él al final monta una empresa que se llama Barral Editores. Yo publiqué ahí una novela divertidísima que se llama Ocho, siete, seis que es la locura y no la tocaron. Es literatura experimental. Yo inventé un personaje como el de El tambor de hojalata. Es un niño monstruo que tiene seis dedos, Ocho, siete, seis: Octavio, Siete días, Seis dedos. Me divertía mucho. La cuenta atrás es porque va a volar el mundo entero porque en un retrete de Wall Street, al tocarlo, vuela todo y solo queda la gente que está escondida en el metro de Madrid. Es una cosa de locos, pero pasa. Barral estaba animadísimo con el libro porque le hacía mucha gracia. Yo he hecho mucha novela y mucho cuento experimental y esos pasaban mejor la censura.

M.Á.V. y C.S.T.: ¿Y Con las manos vacías?

A.F.: Esa fue Premio Ciudad de Barcelona. La sacó Barral. Los premios Ciudad de Barcelona y de Madrid se dan con el libro publicado ya. Cuando se enteró Barral de que le habían dado el premio no entendía nada. ¿Quién presentó la obra? Gente de izquierda. Cuando fuimos allí fue de broma. No quise salir en la tele cuando el Capitán General me diera el premio y dije que estaba enferma mi hija y me volví. Yo ahí digo que no es el Crimen de Cuenca. Las citas, si se ve, están hechas con muy mala leche, sin decir quién las dice: "un publicista de la época dice lo siguiente". Hacíamos toda clase de fintas para engañar a la censura. La narradora es la hija del cura. El crítico Constantino Bértolo dijo que ese era de los pocos libros que es del realismo crítico, no del realismo social, que es contar un hecho social, sino que ahí es una crítica al poder.

La literatura es una aventura de la imaginación del escritor. Es una experiencia de lectura abierta porque depende del que lo lea. Yo no sé la censura lo que piensa. La primera edición es de Barral. Barral era nuestro editor, pero es que lo de Carmen Balcells también conviene estudiarlo. Cuando aparece Balcells, Barral dice "esto es increíble, una idiotez, pobre chica, quién va a hacer eso", pero ella sigue y sigue. Ella nos venía a rogar. Cuando Pacheco publica aquí en Destino Central eléctrica sin tocarle casi nada, sale en la Unión Soviética, que no estaba en la Convención de Berna y hace lo que le da la gana. Le mandan un dineral a Pacheco y entonces "qué Carmen Balcells ni qué ocho cuartos", el Partido Comunista. A Balcells no podíamos dárselo ninguno que fuéramos del Partido.

M.Á.V.y C.S.T.: Cuando llegaban las tachaduras, ¿realizaba usted las modificaciones o lo hacía la editorial?

A.F.: Las hacía la editorial pero me consultaba. Un editor decente, como Barral, tiene que consultar al autor.

Muchas veces yo decía "voy a escandalizar a todo el mundo y que lo prohíban si quieren, a mí qué más me da ya y que Barral lo meta por otro lado" porque Barral siempre me cogía a mí. Cuando hizo Barral Editores él se quedó sin una peseta, entonces nos pidió dinero a los amigos y yo, como estaba en Estados Unidos, le dije "yo te puedo mandar dólares por acciones" y se los mandé porque empezaba de nuevo. Barral no tenía dinero, Barral tenía la editorial, nada más.

M.Á.V. y C.S.T.: ¿En qué medida conserva una obra su valor literario si no se respeta la voluntad de quien la escribe? 
A.F.: Hay que verla como una obra mutilada. Yo digo siempre que el escritor sabe que en la cadena de metáforas que es la lengua es verdad lo que decía William Blake, que si se rompían las puertas de la percepción, se vería que todo es infinito. El escritor siempre anda buscando eso, una cosa infinita.

M.Á.V.y C.S.T.: ¿En qué grado cree que la censura afectó al resultado de sus primeras novelas y a su difusión?

A.F.: Yo creo que mucho, naturalmente. Me prohíben Los vencidos y también Al regreso del Boiras, que el título es de Barral porque yo no sabía cómo llamarle, y es que en esa zona llaman "Boiras" a gente nebulosa. Los Boiras es verdad que existían, esa familia, y cuando regresa ese Boiras de la cárcel se encuentra lo que ha pasado en el pueblo, que es un desastre terrible.

M.Á.V. y C.S.T.: Y si no hubiera intentado publicar con Seix Barral, ¿cree que le bubiera ido mejor con otra editorial?

A.F.: ¿Con qué editorial? No había. Yo he publicado alguna novela con Orígenes, y hay otras novelas mías que nadie conoce, porque no se conoce a las editoriales.

M.Á.V. y C.S.T.: Con respecto al exilio, ¿qué contactos tuvo usted con los exiliados que habia en París?

A. F.: Yo era amigo de Max Aub. Yo conocí a Max Aub a través de un amigo en común. Me fui a México colocado ya por Max Aub, y estaba Max Aub, y León Felipe y tal. Max Aub estaba preparando venir a España, con pasaporte mexicano, para ver cómo era España. Yo lo considero mi maestro porque me organizó muchas cosas. Yo soy maestro de letras por la Universidad de Veracruz, y daba clases allí gracias a Max Aub.

M.Á.V. y C.S.T.: Hablábamos antes del informe de Ocho, siete, seis. ¿Se llegó a plantear que no iba a pasar la censura?

A.F.: Yo sabía que era una cosa disparatada y lo hice un poco de broma. Lo que más me gustaba era lo del falangista, lo del niño que está enamorado de la prostituta, que está saliendo con un falangista cojo, y le corta un escalón, y el falangista se cae y se mata. Sube al cielo y se encuentra a San Pedro que le abre la puerta y le dice: “¿Ves como no hay nada, nada?". Yo me partía. Todos los disparates que se me ocurrían los metía. Porque sabía que a Barral no le importaba, porque Barral publicaba fuera de España. Sin embargo, salió.

M.Á.V. y C.S.T.: Para ir finalizando, desde el final de la dictadura, ¿ ha valorado la posibilidad de reeditar sus obras de forma integra, sin las supresiones o modificaciones de la censura?

A.F.: No, yo no me preocupo de eso. Cuando hago una obra se la dejo a mi editor y ya está. Ya solo pienso en hacer algo nuevo.

\section{Entrevista a Juan Mollá}

Juan Mollá (Paterna, Valencia, 1928) es un abogado y escritor que comenzó su trayectoria literaria a finales de los años cincuenta y en colaboración con su amigo Víctor Alperi, publicando Sueño de sombra (1959), Agua india (1960) y Cristo habló en la montaña (1962). De entre sus títulos en solitario destacan novelas como Segunda Compañia (1963) y El solar (1965) y poemarios como Pie del silencio. Canto al Cares (1958) y Animales impuros (1992). Recientemente, y coincidiendo con su noventa cumpleaños, ha publicado PoeMorias (2018), un libro de poemas en el que revisita su juventud hasta llegar a la actualidad. Como ensayista ha publicado Carlos Bousoño en la poesía de nuestro tiempo (en colaboración con Alperi) (1987) y Teatro español e iberoamericano en Madrid: 1962-1991 (1993). Además, ha sido Presidente del Centro Español de Derechos Reprográficos (CEDRO), uno de los fundadores de la Asociación Literaria y Artística para la Defensa del Derecho de Autor (ALADDA) y también fue fundador y Presidente durante veinte años de la Asociación Colegial de Escritores de España (ACE), de la que ha quedado como Presidente de Honor.

María Álvarez Villalobos y Cristina Suárez Toledano: Durante la redacción de sus obras, cuando tomaba una decisión sobre temática, de léxico..., ¿hasta qué punto tenía presente que los textos que estaba escribiendo serian sometidos a la inspección de la censura? 
Juan Mollá: Lo sabía con certeza por el tema de mis obras. En realidad, todas las novelas que yo escribí y que publiqué en esa época eran peligrosas. Había posibilidad de que no se publicaran. De hecho, varios editores me dijeron que no se podían publicar. De las más castigadas por la censura es Segunda Compañia.

La novela la escribí con el temor de que fuera prohibida, desde luego, pero sobre todo de que molestase al ejército. En mi experiencia como alférez de la Milicia Universitaria en Ibiza, durante el año 55, yo ya me lo imaginaba y tenía cuidado de no poner todo lo que debía poner. Aparte de eso, me interesaba arriesgarme, aunque amigos a los que había dejado el libro (entre otros, tengo el comentario que me hizo un amigo, compañero de carrera y que fue el mejor amigo de esta época, Francisco Rubio Llorente) me advirtieron de que habría cosas que no podrían pasar y yo quise salvar lo más importante para mí, que era el problema del mundo de los soldados y el mundo de los oficiales: el mundo de los miserables, que eran los soldados, y el de los privilegiados, que eran los universitarios. No había un ataque a Franco directamente, aunque pudo haberlo, porque la Segunda Compañía, que era la compañía ejemplar y maravillosa, fue la elegida para hacer el homenaje a Franco cuando fue de visita, de manera que podía haber hecho eso también. Pero eso yo no lo metí en realidad. Personas que conocieron la historia pensaron que me habían cortado eso. Yo no lo metí en ningún momento.

M.Á.V. y C.S.T.: O sea, que se habia autocensurado desde el primer momento, ¿no?

J. M.: Sí, yo sabía que eso no lo podía poner, pero había otras muchas cosas sobre la guerra, sobre la mentalidad de los militares... que ya se sabía que corría un riesgo. Es que en la novela se produce lo siguiente: la novela es prohibida totalmente, pero la novela yo la había presentado a editores que no se habían atrevido a publicarla, pero me dijeron: "preséntala a un premio", entonces yo la presenté al Premio de Novela Plaza y Janés. La premiaron. Entonces la editorial Plaza y Janés la llevaba Mercedes Salisachs. Presentó a la censura la novela y ella misma quitó alguna cosa que era muy fuerte.

M.Á.V.y C.S.T.: ¿Pero se lo consultó a usted?

J.M.: No, eso no, es que era muy fuerte. Entonces ella hizo muchísima publicidad. La cantidad de artículos que se publicaron con el premio y las posibilidades de publicación fueron ingentes. Hablaba gente muy conocida de la novela, de si era militarista o antimilitarista.

\section{M.Á.V.y C.S.T.: ¿Y no se planteó publicarla en el extranjero antes de que se la tacharan?}

J.M.: No, no. No me resultaba fácil. Además, había una revista, $S P$, que decía que no era antimilitar, que era antimilitarista pero no antimilitar. Todo esto fue un bombazo porque me hizo una entrevista en televisión a mediodía, de un cuarto de hora, el presentador principal que había entonces. Él me hizo una entrevista a la hora punta y se enteró todo el mundo, hasta el punto de que yo fui a comprar unos muebles a una tienda y ya lo sabían y me preguntaron: “¿esto es con el dinero del premio?”. Y en la piscina, esto ya no pasa ahora, solo con los best-sellers, la gente me paraba. Entonces había mucha publicidad, y hecha por los grandes. Antonio Tovar, el rector de Salamanca, que era muy conocido, participó. Francisco Fernández Ordóñez escribió para Cuadernos para el Diálogo. Salió mucho comentario antes de que la novela saliera en las librerías. La editorial se había gastado mucho dinero, creían que iba a ser un gran éxito. Quitaron algo para que pasara, pero vamos, que no se logró.

\section{M.Á.V.y C.S.T.: ¿Y se ha planteado desde el final de la dictadura volver a editar la novela sin los cortes?}

J.M.: Sí, sí, al final se editó sin los cortes. La novela no era demasiado fuerte, no era muy dura, podría haber sido mucho más. Mercedes Salisachs vino a Madrid a ver qué podíamos hacer, porque yo le había dicho que no quería que la pusieran con cortes. Nos reuníamos todos los días para ver qué se podía hacer. Ella conocía a Fraga Iribarne, que entonces era el ministro. Ella intentó que se publicara de todas formas y el ministro dijo que sí, pero que teníamos que quitar lo que fuera necesario, adaptarlo un poco. Me dijeron que tenía que hablar con la censura, con el Ministerio, y negociar a ver qué se podía hacer. Yo fui y estuve allí hablando con el jefe. Cortaron un capítulo y cuarenta fragmentos que no eran muy grandes. Eran cortes que podían ser antimilitares. Algunos se les pasaron, porque hay cosas que a mí me parecía que no pasarían y pasaron. Por ejemplo, hay una escena que es de un soldado que está al servicio de un oficial y está llevando a un niño 
y limpiándole el culo al niño y ponía: "hasta el lugar llegó el canto de una tropa. Es tan hermoso ser soldado de la patria”. Eso pasó, no les pareció nada. Y otras cosas las quitaron porque eran más directas.

Se publicó el libro. Después salieron críticas sobre el texto, diciendo que era antimilitar, y algunas durísimas. En la revista Ejército salió un artículo diciendo que no se podía tolerar que yo caminara por las calles de Madrid, que me dejaran andar por las calles de Madrid. Yo era abogado y estaba entonces defendiendo a un soldado. Había muerto una chica que iba en el coche con él y le estaban haciendo un juicio militar. Entonces yo tenía que ir al cuartel a tomarle declaración. En ese cuartel estaba de capellán el capellán que sale en la novela y me llamó por teléfono y me dijo: "Juan, me han dicho que vas a venir a tomar una declaración. Te advierto que se han puesto de acuerdo para darte una paliza a la entrada. No pases por la entrada principal, pasa por detrás y entras por la cocina. Yo te esperaré por la cocina y te pasaré”. El Capitán General de Madrid dirigió una carta muy dura al ministro Fraga protestando porque hubiera autorizado esta novela. Se retiraron los ejemplares que quedaban y se prohibió a la editorial a volver a editarla. Y Plaza y Janés lo cumplió hasta el final. Ya después se publicó, con el capítulo íntegro y los fragmentos.

M.Á.V.y C.S.T.: Usted publicó en distintas editoriales. Antes de enviar algún manuscrito a alguna editorial, ¿tenia en cuenta las relaciones que tenía la censura con esa editorial?

J.M.: Pues no, la verdad es que no. Después de esta novela tuve otra que me la prohibieron: Cuarenta vueltas al sol. Tuve la suerte de que la censora era hermana de un antiguo amigo mío. En la novela, que trataba de la situación de España en esa época, el protagonista ha sido un joven progresista e idealista que participa en el movimiento de mayo del 68 en París, y allí entra en contacto con los movimientos independentistas africanos. Se mete en la empresa de su mujer, que es una gran inmobiliaria, y entonces abandona todas sus ideas y tiene un gran sentimiento de culpabilidad y echa de menos el tiempo en el que era pobre y luchador, cuando luchaba por la libertad del mundo. De pronto, aparece una persona de aquella época, una chica progresista de la que él estaba enamorado, y eso le hace revolver toda su vida. A pesar de la censora, que me echaba una mano, le hicieron tales cortes que yo le dije a la editorial que no la publicaran. La editorial la había impreso ya y cuando la leí me di cuenta de que no se entendía, de que parecía cuestión de un problema conyugal, y dije que no quería que se publicara. Hay ejemplares sueltos, pero no salió a la venta.

M.Á.V. y C.S.T.: ¿Alguna vez consultaba con algún censor, como con la hermana de su amigo, antes de presentar un libro para ver si opinaba si podría salir o no?

J.M.: No. Tuve otro problema, con Fuera de juego. Era mi experiencia como abogado del Frente de Liberación Argelino. Esta es autobiográfica, del asesinato de la secretaria de la oficina. Yo fui abogado del presunto asesino, que era inocente. Esta también tuvo muchos problemas, pero con este libro, que se publica en el año 67, yo era abogado de Camilo José Cela, que era íntimo amigo de Fraga, e incluso comimos juntos un día Cela, Fraga y yo. Fraga era una persona muy animada y todo eran bromas y barbaridades con Cela y Fraga. Pero la pasaron, tuve que cambiar alguna cosa, pero poco. Tuvo muy buena crítica y se hicieron muchas ediciones, pero ese fue otro aspecto de la cuestión.

Yo era abogado y escritor, abogado que llevaba además causas políticas importantes, causas contra la CIA, por ejemplo, la CIA me ha perseguido, y cosas así antifranquistas, y comunistas, y contra EEUU. Tenía el temor de que mi fama como abogado antifranquista llegara a mi fama como persona. Por ejemplo, el embajador de Marruecos, que fue Ministro de Asuntos Exteriores, me dijo "usted es un enemigo de Marruecos", cuando yo solo era un abogado que defendía una causa. Lo digo por el problema de que estás defendiendo algo y, quieras o no, acabas identificándote con eso. Tenía una fama de abogado contrario al régimen. Se daba la circunstancia de que mi padre había estado en la cárcel después de la guerra. Mi infancia fue mi madre con siete hijos y mi padre en la cárcel. Todo eso lo tienes dentro, y lo saben, porque yo estaba siempre, incluso cuando hice el servicio militar, llegaban unos informes sobre mí, que si yo era hijo de tal y cual... En mi caso había el riesgo de que vieran mis obras ya mal desde el principio por ser yo quien era.

Fuera de juego pudo pasar, le quité cosas, pero pudo pasar. 
M.Á.V. y C.S.T.: ¿Usted cree que cuando entró en vigor la Ley de Prensa e Imprenta de 1966 cambió la censura? ¿Cree que se produjo cierta apertura?

J.M.: Es que en el 66 es Fraga. Fraga tuvo muchos ataques por parte de la más extrema derecha por haber hecho esa ley.

M.Á.V. y C.S.T.: ¿En qué medida cree usted que conserva una obra su valor literario si no se respeta la voluntad de quien la escribe?

J.M.: Pues yo creo que realmente pierde su valor. Puede tener un valor formal, pero no el valor de la fuerza con que ha sido escrita, eso clarísimamente es cierto. Lo que pasa es que no sabemos qué hubiera ocurrido si se hubieran publicado las obras tal y como se escribieron. Tampoco hubieran cambiado el mundo, porque realmente se dice que no se publicaron cosas que habrían sido importantísimas, pero la verdad es que después de la muerte de Franco, después de la Democracia, no han aparecido novelas maravillosas escritas durante el franquismo.

M.Á.V. y C.S.T.: Y tampoco muchos autores han decidido reeditar sus obras sin los cortes.

J.M.: No, porque no existían. En gran parte no era verdad. Son ideas que tenían que podían haber hecho pero no estaban escritas. "Yo haría una novela sobre esto, yo sobre esto otro", pero no.

M.Á.V. y C.S.T.: ¿Cree que la censura a veces ayudaba a que un autor se difundiera? Por ejemplo: si no hubiera habido censura podría haber sucedido que la editorial a la que entregó Segunda Compañía no hubiera hecho esa campaña de difusión y no habría tenido éxito. ¿Cree que en ocasiones el hecho de que hubiera censura hacia que la obra censurada tuviese más éxito?

J.M.: Creo que hubiera tenido éxito si se hubiera prohibido y se hubiera publicado inmediatamente, pero yo creo que la censura fue negativa, porque es muy triste que los autores se tuvieran que rebajar al nivel de escribir a la censura para pedir que se aprobaran sus obras, como lo hicieron Dolores Medio o Juan Marsé. Es muy triste que tuvieran que rebajarse a ello. No, yo creo que no, porque prohibido en España y publicado en América, sí, ahí sí.

M.Á.V. y C.S.T.: Claro, pero eso conlleva una consecuente pérdida de lectores españoles, que era el público para el que se escribian diversos temas. ¿Usted se planteó esa cuestión: "publico una obra en el extranjero y no llega a España hasta a saber cuándo pero está integra, o la publico en España con los cortes que va a tener, pero no voy a transmitir toda la idea que quisiera"?

J.M.: Sí, eso era lo que se planteaban los que escribían novelas arriesgadas. Por ejemplo con Cuarenta vueltas al sol, lo que se imprimió poco tenía que ver con lo que había escrito. Y es importante el respeto a la voluntad del autor. Yo he sido abogado de un asunto en el mundo del cine: Javier Marías, con Todas las almas, que la llevaron al cine. La versión traicionaba el pensamiento de la novela de Marías. Además, se había pactado que él controlaría el rodaje, y no se respetó. El productor sacó la obra, pero quien la dirigió fue su hija, y ahí hizo lo que le pareció. No me acuerdo de cómo se llamaba la película. Y ahí, por primera vez, hay una sentencia que da la razón al autor. Consiguió que le indemnizaran y que quitaran de la película que era una versión de la novela de Javier Marías. Esa fue la sentencia, pero luego lo que pasa es que no la cumplieron bien, hubo muchos líos y acabó yendo hasta el Tribunal Supremo... pero Javier Marías se empeñó en que respetaran su novela.

A ningún autor le suelen gustar las películas que se hacen sobre sus novelas, porque son distintas y tal y cual, pero ninguno realmente se ha atrevido a querellarse o a demandar, a enfrentarse al director o productor de la película, que cree que la respeta. Pero Javier sí lo hizo.

M.Á.V. y C.S.T.: Claro, estaba en su derecho, si habian llegado a otro acuerdo... Y, ¿desde el final de la dictadura se ha planteado publicar Cuarenta vueltas al sol, que está inédita en su versión original?

J.M.: No, ya no, porque yo me he entregado mucho más al Derecho luego, y la verdad es que esto era para haberse publicado entonces. La situación de España, decir esto a toro pasado, está todo dicho, se ha vivido después, en la Democracia, todo esto. El público para el que se escribió la novela ya no existe.

Eso le pasó también a Segunda Compañía. El valor que tenía era que se publicó entonces, que había servicio militar, que había ese enfrentamiento, que estaban los soldados, que los soldados eran analfabetos, que el 
30\% de los soldados de mi compañía, de la Segunda Compañía, eran analfabetos. Yo enseñé a leer a veinte chicos. Y entonces estaba el militar universitario, que no era el militar, que hacías unos campamentos y luego unas prácticas ya con los soldados de seis meses. Y entonces, sacar esto, que es en el fondo una denuncia... Sobre todo, las críticas, como la de Paco Fernández Ordóñez, que centra la crítica no en lo militar, sino en la identificación con los humillados, con los perseguidos, con los aplastados, y eso era lo que yo realmente quería hacer ver, la clase: por una parte, los oficiales. En el ejército estaba mal visto que un oficial hablara con un soldado, por ejemplo, que es lo que aquí pasa con el protagonista de la novela. Al protagonista le hacen un juicio, que es el que me hicieron a mí por jugar con los soldados. Y luego los universitarios, ya no los oficiales, sino la clase universitaria, la mayoría de aquella época, frente a los ignorantes, frente a los oprimidos, frente a la pobre gente. Eso ahora, pues ya no. 